\title{
Pediatric trauma burden in Tanzania: analysis of prospective registry data from thirteen health facilities
}

Hendry R. Sawe ${ }^{1,2^{*}}$ (1), Sveta Milusheva ${ }^{3}$, Kevin Croke $^{3,4}$, Saahil Karpe ${ }^{5}$ and Juma A. Mfinanga ${ }^{2}$

\begin{abstract}
Background: Trauma is among the leading causes of morbidity and mortality among pediatric and adolescent populations worldwide, with over ninety percent of childhood injuries occurring in low-income and middle-income countries. Lack of region-specific data on pediatric injuries is among the major challenges limiting the ability of health systems to implement interventions to prevent injuries and improve outcomes. We aim to characterize the burden of pediatric health injuries, initial healthcare interventions and outcomes seen in thirteen diverse healthcare facilities in Tanzania.

Methods: This was a prospective cohort study of children aged up to 18 years presenting to emergency units (EUs) of thirteen multi-level health facilities in Tanzania from $1^{\text {st }}$ October 2019 to $30^{\text {th }}$ September 2020. We describe injury patterns, mechanisms and early interventions performed at the emergency units of these health facilities.

Results: Among 18,553 trauma patients seen in all thirteen-health facilities, 4368 (23.5\%) were children, of whom 2894 (66.7\%) were male. The overall median age was 8 years (Interquartile range 4-12 years). Fall 1592 (36.5\%) and road traffic crash (RTC) 840 (19.2\%) were the top mechanisms of injury. Most patients 3748 (85.8\%) arrived at EU directly from the injury site, using motorized (two or three) wheeled vehicles 2401 (55\%). At EU, 651 (14.9\%) were triaged as an emergency category. Multiple superficial injuries (14.4\%), fracture of forearm (11.7\%) and open wounds (11.1\%) were the top EU diagnoses, while 223 (5.2\%) had intracranial injuries. Children aged 0-4 years had the highest proportion (16.3\%) of burn injuries. Being referred and being triaged as an emergency category were associated with high likelihood of serious injuries with adjusted odds ratio (AOR) 4.18 (95\%Cl 3.07-5.68) and 2.11 (95\%Cl 1.75-2.56), respectively. 1095 (25.1\%) of patients were admitted to inpatient care, 14 (0.3\%) taken to operation theatre, and 25 (0.6\%) died in the EU.
\end{abstract}

Conclusions: In these multilevel health facilities in Tanzania, pediatric injuries accounted for nearly one-quarter of all injuries. Over half of injuries occurred at home. Fall from height was the leading mechanism of injury, followed by RTC. Most patients sustained fractures of extremities. Future studies of pediatric injuries should focus on evaluating various preventive strategies that can be instituted at home to reduce the incidence and associated impact of such injuries.

Keys words: Pediatric injury, Childhood injuries, Tanzania, Africa, Pediatric trauma

\footnotetext{
*Correspondence: hsawe@muhas.ac.tz

1 Department of Emergency Medicine, Emergency Medicine Department,

MUHAS, Muhimbili University of Health and Allied Sciences, P.O.

Box 65001, Dar es Salaam, Tanzania

Full list of author information is available at the end of the article
}

\section{Background}

Injuries are among the major causes of pre-mature and preventable deaths in children across the world (Adeloye et al. 2018). According to the 2020 report of child mortality published by United Nations Inter-agency Group for Child Mortality Estimation, injury is the leading original author(s) and the source, provide a link to the Creative Commons licence, and indicate if changes were made. The images or other third party material in this article are included in the article's Creative Commons licence, unless indicated otherwise in a credit line to the material. If material is not included in the article's Creative Commons licence and your intended use is not permitted by statutory regulation or exceeds the permitted use, you will need to obtain permission directly from the copyright holder. To view a copy of this licence, visit http://creativecommons.org/licenses/by/4.0/. The Creative Commons Public Domain Dedication waiver (http://creativeco mmons.org/publicdomain/zero/1.0/) applies to the data made available in this article, unless otherwise stated in a credit line to the data. 
cause of death for children, adolescents and youth aged 5-24 years (United Nations Inter-agency Group for Child Mortality Estimation (UN-IGME). 'Levels Trends in Child Mortality 2020). Children from low and middle-income countries (LMICs) are disproportionately affected, accounting for over $90 \%$ of unintentional injury related deaths globally (Tupetz et al. 2020; Peden MM, UNICEF, World 2008; World Health Organization 2021). While there have been efforts in reducing the burden of childhood mortality due to trauma in most high-income countries (HIC), in LMIC, efforts have largely focused on addressing mortality resulting from communicable illnesses, leaving a surge in mortality resulting from injuries among the same age population (Adeloye et al. 2018; Sethi et al. 2017; Ademuyiwa et al. 2012). A recent study on global health estimates of child mortality due to injuries in World Health Organisation (WHO) Europe region found a general decline of injuries over a 15-year period; however, there was persistent inequality between the LMICs and HICs in the region, with a widening gap of injury mortality (Sethi et al. 2017). This trend has been attributed to socio-economic transition in these countries, with more urban dwellers and increasing motor vehicle accidents, combined with a lack of injury prevention strategies (Jullien 2021).

In Sub-Saharan Africa (SSA), injuries are a significant cause of mortality, and for every death, there are thousands of non-fatal injuries, which are likely underreported, but result in serious disabilities which might be preventable with timely treatment (WHO 2013; Wesson et al. 2017). While the burden of traumatic injury is very high, many of these injuries can be prevented by simple and cost effective interventions that can be instituted at the community level, targeting children and families (Delmira de Sousa Petersburgo CEK 2010; Sleet 2018). The lack of published trauma data (Croke et al. 2020), and specifically pediatric injury data in the region, prevents comprehensive understanding of factors that are associated with pediatric injuries, care processes and outcomes; all of which can support the development of interventions to prevent injury occurrence, post-injury care and long-term rehabilitation care (Wesson et al. 2017; Herbert et al. 2012; Gallaher et al. 2016).

In Tanzania, like most LMICs, there is paucity of published data on pediatric injury, with few published papers. Most existing literature either focuses on a single cause of injury, such as burn, or they are based on household surveys within a particular geographical context, which limits generalisability of the findings (Simon et al. 2013; Roman et al. 2012; Font et al. 2002; Pérez Méndez et al. 2020). This paucity of data hampers the capacity of health policymakers to understand the burden of pediatric trauma and to prioritize and design effective interventions, such as customizing resources to cater for the needs of management of pediatric injuries (Sleet 2018; Pérez Méndez et al. 2020). In an effort to understand the burden of pediatric injuries, care process and outcome of pediatric injuries in Tanzania, we undertook a study to describe the causes, patterns, interventions and outcomes of pediatric injuries, among patients presenting at the Emergency Units (EUs) of thirteen multi-level health facilities that include the diverse scale of administrative structure of Tanzania's public health infrastructure.

\section{Methods \\ Study design}

This was a prospective cohort study of children 0-18 years that presented to thirteen multi-level health facility EUs in Tanzania from 1st October 2019 to 30th September 2020. In this study, we implemented trauma registries (TRs) at thirteen health facilities, which include four regional hospitals (Tumbi, Morogoro, Dodoma and Mawenzi regional referral hospitals), three district hospitals (Same, Korogwe and Mvomero Hospitals), five health centers (Kimara, Chalinze, Mikumi, Mkata and Gairo health centers) and one dispensary (Fulwe dispensary) (Fig. 1).

\section{Study setting}

This study utilized prospectively collected trauma registry (TR) data from the EU of 13 multi-level health facilities in the United Republic of Tanzania. Tanzania is a lower-middle-income country, with approximately 60 million people, of which over half are aged between 0-19 years (Available from 2021; Bureau and of Statist ics 2016). The public health system operates on a pyramidal model ranging from dispensaries as the lowest level of care to consultant and national level hospitals as the highest level of care (Sirili et al. 2017). There are significant limitations on specialised pediatric neurosurgical trauma care, with such services being available in consultant and national level hospitals. Some regional hospitals have orthopedic and pediatric consultants, but there are substantial limitations around pediatric surgical and orthopedic consultants. All regional and district hospitals have EUs which serve as acute intake areas for patients with acute illness and injuries. While these operate $24 \mathrm{~h}$, seven days a week, there are variable levels of human resource and infrastructure to support care (Sawe et al. 2020). Health centers and dispensaries have dedicated rooms for care of the injured; health centers operate $24 \mathrm{~h}$ per day, while dispensaries operate only for $12 \mathrm{~h}$ per day. The implementation of TR at these facilities was part of a larger trauma study that was aiming at understanding the health impacts of implementing an Emergency Medical 


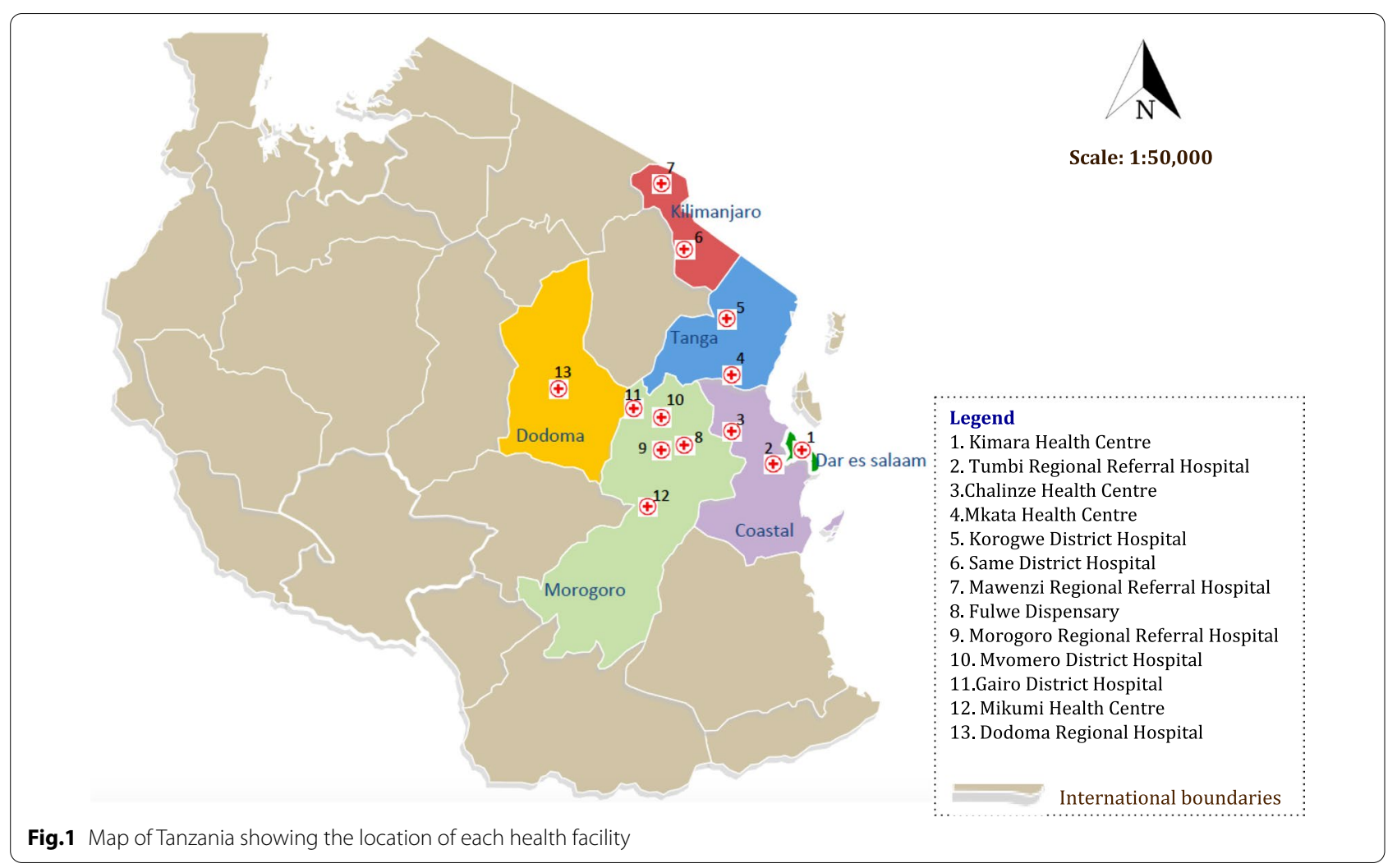

Services (EMS) pilot along the A7 highway that connects Northern to Southern Tanzania (The World Bank 2021). The details and components of pilot implementation of this EMS are discussed elsewhere (Sawe et al. 2021). The TR was set up to enroll all injured patients at EUs of 13 public health facilities that are within two kilometers of the highway, which involved 6 health facilities (which were part of the pilot EMS implementation): 2 regional hospitals (Tumbi and Morogoro), 3 health centers (Kimara, Chalinze and Mikumi) and 1 dispensary (Fulwe). The 7 additional (comparison group) facilities included 2 regional hospitals (Dodoma and Mawenzi), 3 district hospitals (Same, Korogwe and Mvomero) and 2 health centers (Mkata and Gairo), all of which were located on a different though comparable highway. As part of the main study one of the treatment facilities was a dispensary, which functioned more like a health center given the nature and volume of patients presenting to this facility, and therefore, it was better matched with a health center in a comparison group.

\section{Study population}

Children aged 0 to 18 -years-old presenting to any of thirteen health facilities with trauma related complaints, either from the scene of injury or as referral from lower facilities, were eligible for inclusion in the study. We excluded children returning to the EU for follow up care after initial interventions or those who were referred from one of the sites involved in the study.

\section{Data source}

A paper-based standardized trauma documentation form was implemented at the EU of each of thirteen health facilities and was used for both clinical care as well as informing the TR. This standardized trauma form was initially adopted and modified from the World Health Organisation (WHO) standardized trauma form (WHO 2020). Prior to implementation, the paper-based trauma documentation form was modified and re-piloted to ensure inclusion of additional variables of interest, especially related to road traffic injuries (RTI). The final version of the form-included variables related to demographics, injury location, clinical presentation, injury details, injury severity, level and number of injuries, management, care outcomes, diagnosis, consultation and final disposition of the patients. The standardized trauma form was printed with a carbonless copy to allow the duplication of information for clinical documentation as well as retaining a copy that was used for abstracting data to inform the TR. Data from the standardized trauma form were abstracted to an online data capture software 
Research Electronic Data Capture (REDCap) (๔ REDCap version 7.2.2, Vanderbilt, Nashville, TN, USA).

\section{Study procedure}

We recruited and trained a research assistant (RA) and trauma data coordinator (TDC) in each health facility to support data collection. In order to ensure optimal coverage, regional level hospitals had two RAs, while the rest of health facilities had one RA. The TDCs were health care providers in these facilities and had an overall clinical oversight responsibility to ensure compliance and quality of clinical documentation by the clinicians, as well as regular data collection procedures. Prior to launching data collection, we trained RAs and TDCs on the overview of primary trauma care and documentation of variables in the standardized trauma form as well as abstracting data to the REDCap tool using digital tablets.

All patients presenting to the $\mathrm{EU}$ of these health facilities with injury related complaints were manually recorded into the trauma forms by clinicians and RAs. Details of the care process for the patients were expected to be documented by the clinician, while the RA supported the documentation as well as abstracting the information to the REDCap at the end of the patient care process. Clinicians filled out the form $24 \mathrm{~h}$ a day as part of the documentation process when seeing any patient presenting for trauma. This allowed for continuous data collection, and RAs would enter the forms during their working hours. The incoming data were regularly monitored for logical inconsistencies, missing data, outliers, as well as the capture rate per health site. Furthermore, the study authors received copies of completed trauma forms from each site, and performed checks on a randomly selected sample of forms, independently entering the data from the paper form and comparing all variables to those entered by the RAs and provided regular feedback to the TDCs and RAs.

\section{Data analysis}

Data were exported from REDCap and imported onto the Statistical Package for the Social Sciences (SPSS version 22.0, IBM, Ltd, Carolina, USA), cleaned, coded and analyzed. The descriptive statistics of trauma patients were summarized by frequency distribution tables of patient demographics, and mean and standard deviation or median and interquartile range (IQR). Variables analyzed included mechanism of injury, injury intent, triage level, referral pattern and final EU disposition. The final EU diagnoses were coded using International Classification of Diseases (ICD)-10. Logistic regression was performed in order to understand the risk factors for potentially serious injuries (those that necessitated ward, ICU, operating theatre admission or referral to other facilities).

\section{Results}

\section{Patient characteristics}

Among 18,553 trauma patients seen in all thirteenhealth facilities during the study period, 4368 (23.5\%) were children, of whom 2894 (66.7\%) were male, and overall median age was 8 years (Interquartile range 4-12 years). Motorized (two or three) wheeled vehicles 2401 (55\%) were the most common mode of EU arrival; $3748(85.8 \%)$ arrived at EU directly from the injury site. Overall $3223(73.8 \%)$ patients were triaged as priority cases. Table 1

\section{Mechanism, injury intent and place of injury}

Fall from height was the most commonly reported mechanism of injury in the study population, occurring in 1592 (36.4\%) of children. Road traffic injuries were the most common mechanism (31.2\%) in children aged 15 to 18 years of age. Overall most injuries occurred at home (56.0\%), and the majority of injuries $(82.1 \%)$ were unintentional. Table 2

When looking at mechanisms of injury by health facilities, we found that regional hospitals had the highest proportion of patients with fall (43.9\%) and RTC (22.1\%) related injuries, while Health Centers had the highest proportion of stab or cut injuries (17.4\%), animal bite (9.4\%) and burn related injuries $(8.1 \%)$ of which majority 275 (94.5\%) occurred at home, involving touching hot liquid or food. Table 3.

\section{ICD-10 diagnosis by age group and mechanism of injury}

Multiple superficial injuries (14.4\%), fracture of forearm (11.7\%) and open wounds (11.1\%) were the top three diagnoses and accounted for over one-third of diagnoses. Intracranial injuries accounted for $5.2 \%$ of the overall diagnoses. Dog bites (5.3\%) were more common in the age group 5-9 years, while maltreatment syndrome $(4.6 \%)$ was more common in the age group 15 to 18 years. Table 4 . Falls resulted in most extremity fractures, accounting for three quarters of the fractures of forearm (84.8\%), as well as fracture of shoulder and upper arms (84.9\%), while RTCs were responsible for over half (61.4\%) of intracranial injuries Additional file 1.

\section{Nature of injuries with risk factors for serious injuries}

Overall, male patients with AOR 1.17 (95\%CI 1.01-1.35) and those in age group 0 to $<5$ years (AOR: 1.44 (95\%CI 1.14-1.81) had significantly higher likelihood of having serious injuries requiring hospital admission or referral. Being referred and having an initial triage level as an emergency was associated with high likelihood of 
Table 1 Patient characteristics

\begin{tabular}{|c|c|}
\hline & $N=4368$ \\
\hline \multicolumn{2}{|l|}{ Sex* } \\
\hline Male & $2894(66.3 \%)$ \\
\hline Female & 1447 (33.1\%) \\
\hline \multicolumn{2}{|l|}{$\operatorname{Age}^{\mathrm{n}}$} \\
\hline Median (IQR) years & 8 years (IQR: $4-12$ years) \\
\hline Age groups & n (\%) \\
\hline$<5$ years & $1165(26.7)$ \\
\hline $5-9$ years & $1433(32.9)$ \\
\hline 10-14 year & $1040(23.9)$ \\
\hline $15-<18$ years & $676(15.5)$ \\
\hline \multicolumn{2}{|l|}{ Education level ${ }^{\gamma}$} \\
\hline No formal education & $1100(25.2)$ \\
\hline Primary school & $2432(55.7)$ \\
\hline Secondary school & $553(12.7)$ \\
\hline Vocational education & $13(0.3)$ \\
\hline College/ University & $7(0.2)$ \\
\hline \multicolumn{2}{|l|}{ Triage level $\left.\right|^{\sharp}$} \\
\hline Emergency & $651(14.9)$ \\
\hline Priority & $3223(73.8)$ \\
\hline Queue & $430(9.8)$ \\
\hline \multicolumn{2}{|l|}{ Referral status } \\
\hline Direct from injury site & $3748(85.8)$ \\
\hline Referred & $519(11.9)$ \\
\hline Unknown & $101(2.3)$ \\
\hline \multicolumn{2}{|l|}{ Mode of arrival } \\
\hline Motorcycle & $1852(42.4)$ \\
\hline Tricycle & $549(12.6)$ \\
\hline Ambulance & $94(2.2)$ \\
\hline Bicycle & $20(0.5)$ \\
\hline Walk-in & $681(15.6)$ \\
\hline Car & $524(12.0)$ \\
\hline Bus & $10(0.2)$ \\
\hline Mini-bus & $502(11.5)$ \\
\hline Other & $62(1.5)$ \\
\hline Unknown & $74(1.7)$ \\
\hline
\end{tabular}

* 27 (0.6\%) had undocumented gender status

ñ $54(1.2 \%)$ had missing age

H 64 (1.5\%) had missing triage category

$\checkmark 263(6.9 \%)$ had missing education level

serious injuries with AOR 3.17 (95\%CI 2.57-3.90) and 4.18 (95\%CI 3.07-5.68), respectively. Table 5

\section{Final EU disposition by age group}

Most patients 2829 (64.8\%) were discharged from the EU, while $28.2 \%$ of children aged $0-4$ years were admitted to inpatient care, and $10.0 \%$ were referred to higher-level hospitals. The overall EU mortality was 25 (0.6\%), and
$1.0 \%$ of patients aged 5 to 9 years died while receiving care in the EU. Table 6

\section{Discussion}

This study used prospectively collected injury surveillance data from a novel trauma registry implemented at thirteen multilevel health facilities over a period of one year to provide a detailed picture of pediatric injuries treated at health facilities in Tanzania. The findings from this study will provide an evidence base for implementation of appropriate injury prevention strategies, as well as guiding resource allocation to inform care processes at these facilities and other similar settings. In Tanzania, most prior studies on pediatric trauma have been limited to single tertiary sites and have spanned less than one year (Sirili et al. 2017; Sawe et al. 2020). The multisite nature of implementation of this trauma registry involving multilevel facilities with diverse resources, level of care and geographical location, provides a broader picture of the description of burden of pediatric injuries and its associated outcomes in Tanzania.

In these health facilities, pediatric injuries accounted for nearly one-quarter of all trauma cases, highlighting the public health importance of this problem. The peak incidence for injuries in this study is 5 to 9 years of age which is in agreement with prior studies done in similar settings (Sirili et al. 2017; The World Bank 2021). Inability of children to recognize and avoid potential injury risks on their own is one of the unique risks that young children face (Sawe et al. 2021). While the observed high incidence of injury in this age group underscores this fact, it further provides an opportunity for targeted interventions in specific injury settings to reduce the risk and severity of injury (Delmira de Sousa Petersburgo CEK 2010). Similar to previous studies, male children were more affected than females, with a male to female ratio of 2:1. We did not evaluate further the reasons behind this difference, however prior studies have attributed this male preponderance to the overactive nature of male children as compared to female ones (WHO 2020).

In this cohort, one-third of patients were either admitted or referred to higher-level health facilities, with children in the age group 0 to 4 years having the highest proportion of those admitted or referred, compared to other age groups. We evaluated the risk factors for serious injuries, defined by the need for hospitalization, emergency operation or transfer to higher level facilities. Patients who arrived to the EU as referral cases from lower facilities had a significantly higher likelihood of serious injuries compared to those who arrived directly from the injury site. This is likely due to the fact that these patients who are referred to the EU have sustained serious injuries that could not be 
Table 2 Mechanism, intent and injury settings

\begin{tabular}{|c|c|c|c|c|c|}
\hline \multirow{2}{*}{$\begin{array}{l}\text { Variables* } \\
\text { Mechanism }\end{array}$} & \multicolumn{5}{|c|}{ Age distribution (in years) } \\
\hline & Overall $(N=4368)$ & $0-4(n=1165)$ & $5-9(n=1433)$ & $10-14(n=1040)$ & $15-<18(n=676)$ \\
\hline & $n(\%)$ & $\%$ & $\%$ & $\%$ & $\%$ \\
\hline Fall from height & $1592(36.4)$ & 41.4 & 42.9 & 32.6 & 20.3 \\
\hline RTC & $840(19.2)$ & 12.4 & 17.5 & 22.1 & 31.2 \\
\hline Stab or cut & $476(10.9)$ & 5.5 & 11.7 & 14.1 & 13.3 \\
\hline Animal bite & $343(7.9)$ & 4.9 & 9.5 & 9.9 & 6.8 \\
\hline Burn & $291(6.7)$ & 16.2 & 4.0 & 1.4 & 2.5 \\
\hline Blunt trauma & $200(4.6)$ & 3.1 & 3.7 & 5.8 & 7.1 \\
\hline Hit by falling object & $120(2.7)$ & 3.0 & 2.7 & 2.7 & 2.8 \\
\hline Sexual assault & $80(1.8)$ & 0.4 & 1.4 & 2.4 & 4.4 \\
\hline Poisoning & $38(0.9)$ & 1.7 & 0.1 & 0.5 & 1.5 \\
\hline Others ${ }^{H}$ & $230(5.3)$ & 6.8 & 7.5 & 4.3 & 7.0 \\
\hline \multicolumn{6}{|l|}{ Injury intent } \\
\hline Intentional & $147(3.4)$ & 0.8 & 1.8 & 4.8 & 8.7 \\
\hline Unintentional & $3586(82.1)$ & 85.2 & 83.3 & 82.2 & 74.0 \\
\hline Unknown & $635(14.5)$ & 14.1 & 14.9 & 13.0 & 17.3 \\
\hline \multicolumn{6}{|l|}{ Location of injury } \\
\hline Urban & $2468(56.5)$ & $659(56.6)$ & $835(58.3)$ & $562(54.0)$ & $397(58.7)$ \\
\hline Rural & $1633(37.4)$ & $440(37.8)$ & $507(35.4)$ & $413(39.7)$ & $239(35.4)$ \\
\hline Unknown & $267(6.1)$ & $66(5.7)$ & $91(6.4)$ & $65(6.3)$ & $40(5.9)$ \\
\hline \multicolumn{6}{|l|}{ Place of injury } \\
\hline Home & $2445(56.0)$ & 77.2 & 58.7 & 44.0 & 30.3 \\
\hline On the Road & 975 (22.3) & 12.8 & 21.2 & 26.5 & 35.7 \\
\hline School & $355(8.1)$ & 1.6 & 8.9 & 12.6 & 11.4 \\
\hline Work & 159 (3.6) & 3.9 & 2.9 & 3.9 & 4.3 \\
\hline Playground & $107(2.5)$ & 0.1 & 1.6 & 4.0 & 6.1 \\
\hline Public Space & $252(5.8)$ & 3.5 & 5.1 & 6.9 & 9.9 \\
\hline Others & $11(0.3)$ & 0.2 & 0.1 & 0.4 & 0.6 \\
\hline Unknown & $64(1.5)$ & 0.9 & 1.4 & 1.6 & 1.8 \\
\hline
\end{tabular}

54 (1.2\%) had missing age

** 158 (3.6\%) had unknown or missing documentation of mechanism of injury

${ }^{H}$ Others includes gunshot wound, foreign body inhalation, suffocation, drowning

managed by the lower-level facilities due to resources or expertise limitations, and hence necessitated the transfer to higher facilities. Similarly, when a patient is triaged to an emergency category, they had a two-fold likelihood of serious injuries compared to other triage categories. Poisoning as a mechanism of injury was found to be associated with a 2.9 -fold likelihood of serious injuries. There is a lack of dedicated poison treatment centers in Tanzania (Considine et al. 2001), which limits the ability of most facilities to appropriately manage patients with suspected poisoning. Characterizing the nature and severity of poisoning will be key to understanding the resources and expertise needed to inform development of this center in Tanzania and other LICs.
In Tanzania, there is a lack of formal pre-hospital service, which limits the ability of the health system to provide holistic emergency medical services (EMS) to acutely ill and injured patients (Simon et al. 2013). In this study, over three-quarter of patients presented to the EU directly from the injury sites, and the majority used motorized (two or three) wheeler as mode of transport to the EU. The absence of formalized pre-hospital care is not only limiting effective EMS provision, but predisposes injured patients to delay of care access, as well as potential for secondary injuries due to improper handling of victims of injuries (Museru et al. 2004).

In the $\mathrm{EU}$, the majority of patients were triaged to either priority or emergency levels of care, requiring immediate life saving interventions to save their lives or 
Table 3 Mechanism of injury by health facility

\begin{tabular}{|c|c|c|c|c|}
\hline \multirow[t]{2}{*}{ Mechanism of injury** } & $\begin{array}{l}\text { All } \\
N=4368\end{array}$ & $\begin{array}{l}\text { Regional hospitals } \\
N=2171\end{array}$ & $\begin{array}{l}\text { District hospitals } \\
N=502\end{array}$ & $\begin{array}{l}\text { Health centers* } \\
N=1695\end{array}$ \\
\hline & $n(\%)$ & $\%$ & $\%$ & $\%$ \\
\hline Fall & $1592(36.4)$ & 43.9 & 33.5 & 27.8 \\
\hline Road Traffic Crash & $840(19.2)$ & 22.1 & 20.3 & 15.3 \\
\hline Stab or cut & $476(10.9)$ & 6.4 & 8.4 & 17.4 \\
\hline Animal Bite & $343(7.9)$ & 6.8 & 7.4 & 9.4 \\
\hline Burn & $291(6.7)$ & 5.9 & 5.0 & 8.1 \\
\hline Blunt force trauma & $200(4.6)$ & 3.6 & 2.6 & 6.4 \\
\hline Hit by falling object & $120(2.7)$ & 2.4 & 4.0 & 2.8 \\
\hline Sexual Assault & $80(1.8)$ & 1.8 & 3.6 & 1.4 \\
\hline Poisoning & $38(0.9)$ & 0.8 & 1.0 & 0.9 \\
\hline Drowning & $23(0.5)$ & 0.3 & 2.0 & 0.4 \\
\hline Suffocation & $11(0.3)$ & 0.4 & 0.2 & 0.1 \\
\hline Gunshot & $2(0.05)$ & 0.0 & 0.2 & 0.0 \\
\hline Other & $194(4.4)$ & 4.6 & 5.2 & 4.1 \\
\hline
\end{tabular}

* Includes one dispensary

** 158 (3.6\%) had unknown or missing documentation of mechanism of injury

Table 4 ICD-10 diagnosis by age group

\begin{tabular}{|c|c|c|c|c|c|}
\hline \multirow[t]{3}{*}{ ICD-10 diagnosis** } & \multicolumn{5}{|c|}{ Age distribution (in years) } \\
\hline & \multirow{2}{*}{$\begin{array}{l}\text { Overall* }(N=4314) \\
n(\%)\end{array}$} & \multirow{2}{*}{$\begin{array}{l}0-4(n=1165) \\
\%\end{array}$} & \multirow{2}{*}{$\begin{array}{l}5-9(n=1433) \\
\%\end{array}$} & \multirow{2}{*}{$\begin{array}{l}10-14 \\
(n=1040) \\
\%\end{array}$} & \multirow{2}{*}{$\begin{array}{l}15-<18 \\
(n=676) \\
\%\end{array}$} \\
\hline & & & & & \\
\hline Multiple superficial injuries, unspecified & $622(14.4)$ & 13.1 & 12.1 & 16.2 & 18.5 \\
\hline Fracture of forearm & $505(11.7)$ & 7.9 & 14.0 & 13.7 & 9.9 \\
\hline Open wound of unspecified body region & $481(11.1)$ & 6.4 & 12.2 & 13.3 & 12.3 \\
\hline Fracture of shoulder and upper arm & $385(8.9)$ & 9.4 & 12.8 & 6.3 & 3.7 \\
\hline Burns and corrosions & $296(6.9)$ & 16.3 & 3.9 & 1.5 & 3.0 \\
\hline Open wounds involving multiple body regions & $232(5.4)$ & 4.4 & 5.0 & 5.9 & 7.0 \\
\hline Bitten or struck by dog & $228(5.3)$ & 3.4 & 7.4 & 5.3 & 3.8 \\
\hline Fracture of lower leg, including ankle & $226(5.2)$ & 3.9 & 5.7 & 5.7 & 5.9 \\
\hline Intracranial injury & $223(5.2)$ & 5.7 & 4.8 & 4.3 & 5.9 \\
\hline Fracture of femur & $207(4.8)$ & 5.8 & 4.8 & 4.0 & 3.3 \\
\hline Maltreatment syndrome & $79(1.8)$ & 0.5 & 1.2 & 2.4 & 4.6 \\
\hline Effects of foreign body entering through natural orifice & $70(1.6)$ & 4.0 & 1.1 & 0.7 & 0.0 \\
\hline Bitten or struck by other mammals & $69(1.6)$ & 0.3 & 0.9 & 3.6 & 2.2 \\
\hline Sprain and strain of other and unspecified parts of foot & $68(1.6)$ & 2.5 & 1.3 & 1.3 & 1.0 \\
\hline Fracture at wrist and hand level & $67(1.6)$ & 1.1 & 1.2 & 2.0 & 2.4 \\
\hline Fracture unspecified & $56(1.3)$ & 1.4 & 1.0 & 1.9 & 0.7 \\
\hline Dislocation, sprain and strain of joints and ligaments of elbow & $38(0.9)$ & 1.1 & 1.3 & 0.6 & 0.1 \\
\hline Contact with hornets, wasps and bees & $34(0.8)$ & 1.1 & 0.7 & 0.9 & 0.3 \\
\hline Dislocation unspecified & $34(0.8)$ & 1.1 & 0.8 & 0.7 & 0.1 \\
\hline Poisoning by, adverse effects of and under dosing of drugs & $33(0.8)$ & 1.4 & 0.1 & 0.3 & 1.8 \\
\hline
\end{tabular}

" Overall 54 patients were missing age. **These are top 20 EU diagnoses, only primary diagnosis was included, and 153 patients were missing final EU diagnosis 
Table 5 Risk factors for serious injuries

\begin{tabular}{|c|c|c|c|c|c|}
\hline Variable & $\begin{array}{l}\text { Overall } \\
N=4368\end{array}$ & $\begin{array}{l}\text { Non-discharged* } \\
n(\%)\end{array}$ & $\begin{array}{l}\text { Unadjusted OR } \\
\text { UOR }[95 \% \mathrm{Cl}]\end{array}$ & $\begin{array}{l}\text { Adjusted OR } \\
\text { AOR }[95 \% \mathrm{Cl}]\end{array}$ & $p$ value \\
\hline \multicolumn{6}{|l|}{ Mechanism of injury } \\
\hline Fall & 1592 & $678(42.6)$ & $1.92(95 \% C l 1.42-2.61)$ & $1.93(95 \% \mathrm{Cl} 1.42-2.63)$ & $<0.0001$ \\
\hline RTC & 840 & $386(45.9)$ & $2.20(95 \% \mathrm{Cl} 1.60-3.03)$ & $2.35(95 \% \mathrm{Cl} 1.69-3.28)$ & $<0.0001$ \\
\hline Stab or cut & 476 & $31(6.5)$ & 0.18 (95\%Cl 0.11-0.29) & $0.24(95 \% \mathrm{Cl} 0.15-0.38)$ & $<0.0001$ \\
\hline Animal bite & 343 & $36(10.5)$ & 0.30 (95\%Cl 0.19-0.48) & $0.38(95 \% \mathrm{Cl} 0.24-0.61)$ & $<0.0001$ \\
\hline Burn & 291 & $150(51.5)$ & 2.76 (95\%Cl 1.91-3.99) & $3.00(95 \% \mathrm{Cl} 2.01-4.49)$ & $<0.0001$ \\
\hline Blunt force trauma & 200 & $32(16.0)$ & $0.49(95 \% \mathrm{Cl} 0.31-0.79)$ & $0.57(95 \% \mathrm{Cl} 0.35-0.93)$ & 0.025 \\
\hline Hit by falling object & 120 & $26(21.7)$ & $0.72(95 \% \mathrm{Cl} 0.43-1.21)$ & 0.85 (95\%Cl 0.49-1.46) & 0.559 \\
\hline Sexual assault & 80 & $23(28.8)$ & 1.05 (95\%Cl 0.59-1.84) & $1.30(95 \% \mathrm{Cl} 0.73-2.35)$ & 0.368 \\
\hline Poisoning & 38 & $18(47.4)$ & $2.33(95 \% C l$ 1.16-4.69) & $2.87(95 \% \mathrm{Cl} 1.39-5.89)$ & 0.004 \\
\hline Others & 230 & $64(27.8)$ & Ref & Ref & \\
\hline$A g e^{\check{n}}$ & $N=4368$ & & & & \\
\hline$<5$ years & 1165 & $446(38.3)$ & 1.45 (95\%Cl 1.18-1.77) & $1.44(95 \% \mathrm{Cl} 1.14-1.81)$ & 0.002 \\
\hline $5-9$ years & 1433 & $470(32.8)$ & 1.13 (95\%Cl 0.93-1.39) & $1.12(95 \% \mathrm{Cl} 0.9-1.41)$ & 0.3 \\
\hline 10-14 year & 1040 & $330(31.7)$ & 1.08 (95\%Cl 0.88-1.34) & $0.98(95 \% \mathrm{Cl} 0.77-1.24)$ & 0.849 \\
\hline $15-18$ years & 676 & $203(30.0)$ & Ref & Ref & \\
\hline Referral $^{H}$ & $N=4267$ & & & & \\
\hline Direct from injury site & 3748 & $1142(30.5)$ & Ref & Ref & \\
\hline Referred & 519 & $308(59.3)$ & $3.33(95 \%$ Cl 2.76-4.02) & $3.17(95 \% \mathrm{Cl} 2.57-3.90)$ & $<0.0001$ \\
\hline Triage level ${ }^{n}$ & $N=4304$ & & & & \\
\hline Emergency & 651 & $334(51.3)$ & 3.93 (95\%Cl 2.97-5.18) & $4.18(95 \% \mathrm{Cl} 3.07-5.68)$ & $<0.0001$ \\
\hline Priority & 3223 & $1033(32.1)$ & 1.76 (95\%Cl 1.38-2.24) & $1.89(95 \%$ Cl 1.45-2.49) & $<0.0001$ \\
\hline Queve & 430 & $91(21.2)$ & Ref & Ref & \\
\hline Injury intent ${ }^{\rho}$ & $N=3733$ & & & & \\
\hline Intentional injuries & 147 & $50(34.0)$ & Ref & Ref & \\
\hline Unintentional injuries & 3586 & $1171(32.7)$ & 0.98 (95\%Cl 0.64-1.39) & $0.99(95 \% \mathrm{Cl} 0.67-1.48)$ & 0.99 \\
\hline Gender** & $N=4341$ & & & & \\
\hline Male & 2894 & $1008(34.8)$ & 1.16 95\%Cl (1.01-1.33) & $1.17(95 \%$ Cl 1.01-1.35) & 0.041 \\
\hline Female & 1447 & $456(31.5)$ & Ref & Ref & \\
\hline
\end{tabular}

* Included injuries requiring hospital admission, operation theatre procedure or referral to higher level of care

n้ 54 (1.2\%) had missing age, ${ }^{* *} 27(0.6 \%)$ had undocumented gender status, ${ }^{\sharp} 101$ had unknown referral status

ň Emergency: to be seen immediately, and, priority: to be seen within a few minutes of arrival

${ }^{\rho}$ In 635 , (14.5\%) patients intention of injury was unknown

Table 6 Final EU disposition by age group

\begin{tabular}{|c|c|c|c|c|c|}
\hline \multirow[t]{3}{*}{ Disposition* } & \multicolumn{5}{|c|}{ Age distribution (in years) } \\
\hline & Total $N=4368^{\mathrm{n}}$ & $0-4 n=1165$ & 5 to $9 n=1433$ & $\begin{array}{l}10 \text { to } 14 \\
n=1040\end{array}$ & 15 to $18 n=676$ \\
\hline & $n(\%)$ & $\%$ & $\%$ & $\%$ & $\%$ \\
\hline Discharged home & $2829(64.8)$ & 60.3 & 65.5 & 66.8 & 68.5 \\
\hline Admitted to ward & $1095(25.1)$ & 28.2 & 23.4 & 23.8 & 24.6 \\
\hline Transferred to another facility & $363(8.3)$ & 10.0 & 8.9 & 7.5 & 5.2 \\
\hline Died at ED & $25(0.6)$ & 0.4 & 1.0 & 0.3 & 0.4 \\
\hline Admitted to Operating Theatre (OT) & $14(0.3)$ & 0.1 & 0.5 & 0.4 & 0.3 \\
\hline Unknown & $42(1.0)$ & 1.0 & 0.8 & 1.2 & 1.0 \\
\hline
\end{tabular}

n̆ 54 (1.2\%) had missing age 
prevent lifelong disabilities. In patients presenting with acute illness or injuries, the initial triage level has been associated with both level of resource utilization as well as the clinical outcomes of patients (Gome et al. 2005). These findings indicate the need to further evaluate the outcome, resources availability and referral patterns of pediatric patients based on the initial level of triage which can be used in guiding the development of protocols for care and referral.

Most injuries were unintentional, occurred at home and resulted from a fall as the main mechanism of injury, which is in concordance with prior studies (Adesunkanmi et al. 1998). Playing has been described as the most common activity at the time of domestic injuries in pediatric patients (Stracciolini et al. 2014). Homebased safety interventions have been shown to reduce injury related admissions in HICs (Hill et al. 2021; Watson and Errington 2016). Given that most injuries in this study occurred at home, a setting that is usually perceived to be safe by parents, plans to reduce the incidence of home related injuries would require devising and testing context appropriate home-safety interventions at different stages of children's growth. Interestingly, when we analyzed the age specific mechanisms of injury, we found that as the age increases (from $0-4$ years to $15-<18$ years) the settings change from home to the road, as well as increase in the proportion of intentional injuries. We believe that this is due to the fact that with increasing age, there is a likelihood of children taking part in daily activities and outdoor sports independently and hence predisposing themselves to risk of RTC and other outdoor injuries, as well as intentional injuries (Mbarouk et al. 2017; Kuzma et al. 2015).

Fracture of the forearm, fracture of shoulder and fracture of the upper arm accounted for the majority fractures of extremities, a finding that is in concordance with most of the previously published studies of pediatric injuries (Kuzma et al. 2015). The peak incidence of injuries of extremities was at the age group of 5 to 10 years, which corresponds to our observed high incidence of fall as a mechanism of injury recorded in this age group. In previously published studies, intracranial injuries have been associated with poor clinical progression and outcomes (Kuzma et al. 2015). In our study population, intracranial injuries accounted for five percent of the final EU diagnosis with an equal distribution across all age groups. Evaluation of the long-term sequelae of these injuries will enable understanding of resources and capacity at each of these facilities, as well as the associated outcomes. Similar to previously published studies (Ahn et al. 2011 Aug), burn injuries were found to be fairly common in this study population and were mostly concentrated in the age group 0-4 years, which had 4-11 times higher incidence compared to other age groups. In this age group, nearly all burn injuries occurred at home, with over ninety percent resulting from touching hot liquid or food. Community level education on prevention of accidental burns at home targeting heads of household, with focus on cost-effective infrastructure improvement, and child caregivers can have impact on reducing the incidence burn injuries in this age group (Outwater et al. 2013).

\section{Limitations}

This study included patients from a purposefully selected sample of health facilities that were located close to strategically busy highways in Tanzania, and hence may limit its generalisability to the rest of health facilities in the country. However, we believe the multilevel nature of these health facilities, ranging from lower (dispensary) to the tertiary (regional hospital) level has provided an opportunity to better understand the burden of pediatric injuries at these different levels. The overall TR capture rate was not $100 \%$, we had specific gaps in capturing patients who were dead on arrival at the facility. These patients did not pass through the emergency medical department at most facilities but were taken directly to the mortuaries, which resulted in the low capture rate for some facilities. Furthermore, the COVID-19 pandemic impacted our overall data collection process, as we had to withdraw research assistants and have them work from home to minimize risk of disease transmission, hence affecting the quality of data collection. However, using a standardized clinical documentation form filled out by clinicians ensured that care to the patient and data collection was maintained during the study period.

\section{Conclusions}

In these multilevel health facilities in Tanzania, pediatric injuries accounted for nearly one-quarter of all injuries. Over half of injuries occurred at home, fall from height was the leading mechanism of injury, followed by RTC. Only two percent of patients arrived at EU by ambulance. Patients who arrived to the EU as referral cases, those triaged as emergency category had more than two-fold likelihood of serious injuries requiring hospitalization, emergency operation or transfer to higher levels of care. Future studies of pediatric injuries should focus on evaluating various preventive strategies that can be instituted at home to reduce the incidence and associated impact of such injuries, as well as evaluation of transport systems between healthcare facilities or from the scene and consideration for development of a formal emergency medical service system. 


\section{Supplementary Information}

The online version contains supplementary material available at https://doi. org/10.1186/s40621-022-00369-7.

Additional file 1: Supplementary Table 1. Mechanism of injury by health facility. Supplementary Table 2. Gander by mechanism of injury.

\section{Acknowledgements}

We would like to thank the Ministry of Health, Community Development, Gender, Elderly and Children (MoHCDGEC), President's Office Regional Administration and Local Government (PORALG), Ministry of Works, Transport and Communications and the Ministry of Home Affairs (Traffic Police Division) for their support in the process of setting up and data collection of this project. We thank Ms. Chiku Simbano, Mr. Ramadhani Mashoka, Ms. Kriti Malhotra, Ms. Doreen Shango, Ms. Meyhar Mohammed, Ms. Jonna Margaret Bertfelt, as well as the incharge of each health facility, Trauma Data Coordinators and Research Assistants for their research assistance in collection of this data. We would also like to thank the World Bank Country Office in Tanzania, especially the Health sector team members, including Inaam UI Haq, Peter Okwero, Mariam Ally and Chiho Suzuki, for their support; as well as the World Bank Operations project leads, Gylfi Palsson and Dominic Haazen. The findings, interpretations and conclusions expressed in this paper do not necessarily reflect the views of the World Bank, the Executive Directors of the World Bank or the governments whom they represent. The World Bank does not guarantee the accuracy of the data included in this work.

\section{Authors' contributions}

HRS and JAM contributed to the conception and design of the study, acquired, analyzed and interpreted the data, and drafted the manuscript. SM contributed to the conception and design of the data collection, data acquisition, data monitoring, data cleaning, interpretation and fundraising. KC contributed to the conception and design of the data collection and fundraising and assisted with data interpretation. SK contributed to the conception and design of the data collection, data monitoring and fundraising. All authors read, revised and approved of the final manuscript.

\section{Funding}

This project was fully funded by the UK Aid Foreign Commonwealth \& Development Office (FCDO) of the United Kingdom Government, including through the ieConnect for Impact Program as well as through support from the Research Support Budget in the Development Economics Vice-Presidency of the World Bank.

\section{Availability of data and materials}

The datasets used and/or analyzed during the current study are available on request from Principal Administrators.

\section{Declarations}

\section{Ethics approval and consent to participate}

The study protocol was reviewed and approved by the National Health Research Ethics Review Committee (NatREC) and Institutional Review Board of the Muhimbili University of Health and Allied Sciences (MUHAS). As no patient or provider identifying details were kept, and no patient contact was made, the IRB approved a waiver of patient consent.

\section{Permission to publish}

The permission to publish was obtained from the National Health Research Ethics Review Committee (NatREC).

\section{Competing interests}

The authors declare no conflicts of interest.

\section{Author details}

${ }^{1}$ Department of Emergency Medicine, Emergency Medicine Department, MUHAS, Muhimbili University of Health and Allied Sciences, P.O. Box 65001 Dar es Salaam, Tanzania. ${ }^{2}$ Department of Emergency Medicine, Muhimbili National Hospital, Dar es Salaam, Tanzania. ${ }^{3}$ Development Impact Evaluation
Group, World Bank, Washington, DC, USA. ${ }^{4}$ Harvard T. H. Chan School of Public Health, Boston, MA, USA. ${ }^{5}$ Lyft, San Francisco, CA, USA.

Received: 29 September 2021 Accepted: 7 January 2022

Published online: 17 January 2022

\section{References}

Adeloye D, Bowman K, Chan KY, Patel S, Campbell H, Rudan I. Global and regional child deaths due to injuries: an assessment of the evidence. J Glob Health. 2018;8(2):021104.

Ademuyiwa AO, Usang UE, Oluwadiya KS, Ogunlana DI, Glover-Addy H, Bode $\mathrm{CO}$, et al. Pediatric trauma in sub-Saharan Africa: challenges in overcoming the scourge. J Emerg Trauma Shock. 2012;5(1):55-61.

Adesunkanmi ARK, Oginni LM, Oyelami AO, Badru OS. Epidemiology of childhood injury. J Trauma Inj Infect Crit Care. 1998;44(3):506-11.

Ahn H, Singh J, Nathens A, MacDonald RD, Travers A, Tallon J, et al. Pre-hospital care management of a potential spinal cord injured patient: a systematic review of the literature and evidence-based guidelines. J Neurotrauma. 2011;28(8):1341-61.

The World Bank. The World Bank in Tanzania [Internet]. 2021. https://www. worldbank.org/en/country/tanzania

National Bureau of Statist ics T. Tanzania in Figures, 2016 [Internet]. Tanzania Bureau of Statistics; 2017. www.nbs.go.tz.

Considine J, Ung L, Thomas S. Regular article. Accid Emerg Nurs. 2001;9(2):101-8.

Croke K, Chokotho L, Milusheva S, Bertfelt J, Karpe S, Mohammed M, et al. Implementation of a multi-center digital trauma registry: Experience in district and central hospitals in Malawi. Int J Health Plann Manage. 2020;35(5):1157-72.

Delmira de Sousa Petersburgo CEK. The epidemiology of childhood injury in Maputo. Mozambique Int J Emerg Med. 2010;3(3):157-63.

Font F, Quinto L, Masanja H, Nathan R, Ascaso C, Menendez C, et al. Paediatric referrals in rural Tanzania: the Kilombero District Study - a case series. BMC Int Health Hum Rights. 2002;2(1):4.

Gallaher JR, Molyneux E, Charles AG. Sub-Saharan African hospitals have a unique opportunity to address intentional injury to children. Afr J Emerg Med Rev Afr Med Urgence. 2016;6(2):59-60.

Gome DL, Mutiso VM, Kimende K. Paediatric trauma at Kenyatta National Hospital, Nairobi Kenya. East Cent Afr J Surg. 2005;10(2):33-6.

Herbert HK, van As AB, Bachani AM, Mtambeka P, Stevens KA, Millar AJW, et al. Patterns of pediatric injury in South Africa: an analysis of hospital data between 1997 and 2006. J Trauma Acute Care Surg. 2012;73(1):168-74.

Hill T, Coupland C, Kendrick D, Jones M, Akbari A, Rodgers S, et al. Impact of the national home safety equipment scheme "Safe At Home" on hospital admissions for unintentional injury in children under 5: a controlled interrupted time series analysis. J Epidemiol Community Health. 2021 Jun 22;jech-2021-216613.

Jullien S. Prevention of unintentional injuries in children under five years. BMC Pediatr. 2021;21(Suppl 1):311.

Kendrick D, Young B, Mason-Jones AJ, Ilyas N, Achana FA, Cooper NJ, et al. Home safety education and provision of safety equipment for injury prevention (Review). Evid-Based Child Health Cochrane Rev J. 2013;8(3):761939. https://doi.org/10.1002/ebch.1911.

Kuzma K, Lim AG, Kepha B, Nalitolela NE, Reynolds TA. The Tanzanian trauma patients' prehospital experience: a qualitative interview-based study. BMJ Open. 2015;5(4):e006921.

Mbarouk GS, Sawe HR, Mfinanga JA, Stein J, Levin S, Mwafongo V, et al. Patients with acute poisoning presenting to an urban emergency department of a tertiary hospital in Tanzania. BMC Res Notes. 2017;10:482. https://doi. org/10.1186/s13104-017-2807-2.

Museru L, Leshabari M, Mbembati N. Patterns of road traffic injuries and associated factors among school-aged children in Dar es Salaam, Tanzania|African Safety Promotion: A Journal of Injury and Violence Prevention. Afr Saf Promot J Inj Violence Prev 2004;1(2002):1. https://www. ajol.info/index.php/asp/article/view/31535

Ndungu A, Sun J, Musau J, Ndirangu E. Patterns and outcomes of paediatric trauma at a tertiary teaching hospital in Kenya. Afr J Emerg Med. 2019;9:S47-51. 
Odondi RN, Shitsinzi R, Emarah A. Clinical patterns and early outcomes of burn injuries in patients admitted at the Moi Teaching and Referral Hospital in Eldoret, Western Kenya. Heliyon. 2020;6(3):e03629.

Outwater AH, Ismail H, Mgalilwa L, Justin Temu M, Mbembati NA. Burns in Tanzania: morbidity and mortality, causes and risk factors: a review. Int J Burns Trauma [Internet]. 2013;3(1):18-29.

Peden MM, UNICEF, World Health Organization, editors. World report on child injury prevention. Geneva, Switzerland: [New York, NY]: World Health Organization ; UNICEF; 2008. 211 p.

Pérez Méndez MA, Kigwangalla HA, Bärnighausen T, Lowery Wilson M. Injuries among children and adolescents in a rapidly growing urban African metropolis: a cross-sectional survey of 1,968 households in Dar es Salaam. Tanzania PeerJ. 2020;8:e10048.

Roman IM, Lewis ER, Kigwangalla HA, Wilson ML. Child burn injury in Dar es Salaam, Tanzania: results from a community survey. Int J Inj Contr Saf Promot. 2012;19(2):135-9.

Sawe HR, Reynolds TA, Weber EJ, Mfinanga JA, Coats TJ, Wallis LA. Trauma care and capture rate of variables of World Health Organisation data set for injury at regional hospitals in Tanzania: first steps to a national trauma registry. BMC Emerg Med. 2020;20(1):29.

Sawe HR, Milusheva S, Croke K, Karpe S, Mohammed M, Mfinanga JA. Burden of Road Traffic Injuries in Tanzania: One-Year Prospective Study of Consecutive Patients in 13 Multilevel Health Facilities. Fedeli P, editor. Emerg Med Int [Internet]. 2021;1-9. https://www.hindawi.com/journals/emi/ 2021/4272781/

Sethi D, Aldridge E, Rakovac I, Makhija A. Worsening inequalities in child injury deaths in the WHO European region. Int J Environ Res Public Health. 2017;14(10):E1128.

Simon R, Gilyoma JM, Dass RM, Mchembe MD, Chalya PL. Paediatric injuries at Bugando Medical Centre in Northwestern Tanzania: a prospective review of 150 cases. J Trauma Manag Outcomes. 2013;7(1):10.

Simon R, Gilyoma JM, Dass RM, Mchembe MD, Chalya PL. Paediatric injuries at Bugando medical Centre in northwestern Tanzania: a prospective review of 150 cases. J Trauma Manag Outcomes [Internet]. 2013;7(1):10.

Sirili N, Kiwara A, Gasto F, Goicolea I, Hurtig A-K. Training and deployment of medical doctors in Tanzania post-1990s health sector reforms: assessing the achievements. Hum Resour Health. 2017. https://doi.org/10.1186/ s12960-017-0202-7.

Sleet DA. The global challenge of child injury prevention. Int J Environ Res Public Health. 2018;15(9):E1921.

Stracciolini A, Casciano R, Levey Friedman H, Stein CJ, Meehan WP, Micheli LJ. Pediatric sports injuries: a comparison of males versus females. Am J Sports Med. 2014;42(4):965-72.

The World Bank. Southern Africa Trade and Transport Facilitation Project [Internet]. World Bank Projects and Operations. [cited 2021 Oct 26]. http://proje cts.worldbank.org/P120370/southern-africa-trade-transport-facilitationproject?lang $=$ en\&tab $=$ details

Tupetz A, Friedman K, Zhao D, Liao H, Isenburg MV, Keating EM, et al. Prevention of childhood unintentional injuries in low- and middle-income countries: A systematic review. PLOS ONE. 2020;15(12):e0243464. https:// doi.org/10.1371/journal.pone.0243464

United Nations Inter-agency Group for Child Mortality Estimation (UN-IGME). Levels \& trends in child mortality: Report 2020, estimates developed by the united nations inter-agency group for child mortality estimation. United Nations Children's Fund, New York; 2020.

Watson MC, Errington G. Preventing unintentional injuries in children: successful approaches. Paediatr Child Health [Internet]. 2016;26(5):194-9.

Wen LS, Geduld HI, Nagurney JT, Wallis LA. Africa's first emergency medicine training program at the University of Cape Town/Stellenbosch University: history, progress, and lessons learned. Acad Emerg Med off J Soc Acad Emerg Med. 2011;18(8):868-71.

Wesson HKH, Bachani AM, Mtambeka P, Schulman D, Mavengere C, Ward Millar $\mathrm{AJ}$, et al. Changing state of pediatric injuries in South Africa: An analysis of surveillance data from a Pediatric Emergency Department from 2007 to 2011. Surgery. 2017;162(6S):S4-11.

WHO | World report on child injury prevention [Internet]. WHO. [cited 2013 Nov 24]. http://www.who.int/violence_injury_prevention/child/injury/ world_report/en/

WHO. WHO Standardized Clinical Form [Internet]. WHO Standardized Clinical Form. 2020. https://www.who.int/publications/i/item/who-standardiz ed-clinical-form
World Health Organization. Global status report on road safety 2018 [Internet]. World Health Organization; 2021 Oct [cited 2021 Oct 26]. https://www. who.int/publications/i/item/9789241565684

\section{Publisher's Note}

Springer Nature remains neutral with regard to jurisdictional claims in published maps and institutional affiliations.
Ready to submit your research? Choose BMC and benefit from:

- fast, convenient online submission

- thorough peer review by experienced researchers in your field

- rapid publication on acceptance

- support for research data, including large and complex data types

- gold Open Access which fosters wider collaboration and increased citations

- maximum visibility for your research: over $100 \mathrm{M}$ website views per year

At BMC, research is always in progress.

Learn more biomedcentral.com/submissions 